\title{
Workflow for robust Scholte and Love waves phase- velocity estimation from small aperture Ocean Bottom Seismometer arrays in Lake Lucerne: deployment, location, orientation, and clock error correction
}

Agostiny Marrios Lontsi ( $\square$ agostiny.lontsi@sed.ethz.ch )

Swiss Seismological Service, ETH Zurich https://orcid.org/0000-0002-7773-5510

Anastasiia Shynkarenko

Swiss Seismological Service, ETH Zurich

Katrina Kremer

Swiss Seismological Service, ETH Zurich

Manuel Hobiger

Swiss Seismological Service, ETH Zurich

\section{Paolo Bergamo}

Swiss Seismological Service, ETH Zurich

\section{Stefano C. Fabbri}

Institute of Geological Sciences and Oeschger Centre for Climate Change Research, University of Bern

Flavio S. Anselmetti

Institute of Geological Sciences and Oeschger Centre for Climate Change Research, University of Bern Donat Fäh

Swiss Seismological Service, ETH Zurich

\section{Research Article}

Keywords: Ambient vibrations, OBS, Clock error, Misorientation, Phase-velocity

Posted Date: June 17th, 2021

DOI: https://doi.org/10.21203/rs.3.rs-559556/v1

License: (c) (i) This work is licensed under a Creative Commons Attribution 4.0 International License. Read Full License 


\title{
Workflow for robust Scholte and Love waves phase-velocity estimation from small aperture Ocean Bottom Seismometer arrays in Lake Lucerne: deployment, location, orientation, and clock error correction
}

\author{
Agostiny Marrios Lontsi ${ }^{1}$ • Anastasiia \\ Shynkarenko $^{1}$. Katrina Kremer ${ }^{1,2}$. Manuel \\ Hobiger $^{1}$. Paolo Bergamo ${ }^{1}$. Stefano C. \\ Fabbri $^{2}$ - Flavio S. Anselmetti ${ }^{2}$. Donat Fäh ${ }^{1}$
}

Received: date / Accepted: date

\begin{abstract}
The phase-velocity dispersion curve (DC) is an important characteristic of the propagation of surface waves in sedimentary environments. Although the procedure for DC estimation in onshore environments using ambient vibration recordings is well established, the DC estimation in offshore environments using arrays of Ocean Bottom Seismometers (OBS) presents three main challenges. These are the localization, the orientation of the OBS horizontal components, and the clock error.

Here, we concentrate on the workflow for a robust estimation of the phase-velocity dispersion curves from small aperture OBS array measurements in Lake Lucerne (Switzerland). OBS array campaigns were performed between 2018 and 2020 using arrays with a maximum aperture of $679 \mathrm{~m}$ at a maximum water depth of 81 $\mathrm{m}$. The challenges related to the OBS location on the lake floor were addressed by combining the multibeam bathymetry map and the backscatter image for the investigated site with the differential GPS coordinates of the OBS at recovery. The OBS measurements were complemented by airgun surveys. Airgun data were first used to estimate the misorientation of the horizontal components of the OBS and second to estimate the clock error. Finally, we use two array processing methods, namely the three-component high-resolution frequency-wavenumber and the interferometric multichannel analysis of surface waves, to estimate the dispersion characteristics of the propagating surface waves for one of the array sites. We clearly observe the phasevelocity dispersion curve branches for Scholte and Love waves in the frequency range between 1.2 and $3.2 \mathrm{~Hz}$ for both array processing techniques.
\end{abstract}

\footnotetext{
${ }^{1}$ Swiss Seismological Service, ETH Zurich, Sonneggstrasse 5, 8092 Zurich, Switzerland

E-mail: agostiny.lontsi@sed.ethz.ch, a.shynkarenko@sed.ethz.ch, katrina.kremer@sed.ethz.ch, manuel.hobiger@sed.ethz.ch, paolo.bergamo@sed.ethz.ch, donat.faeh@sed.ethz.ch

2 Institute of Geological Sciences and Oeschger Centre for Climate Change Research, University of Bern, Baltzerstrasse 1+3, 3012 Bern, Switzerland E-mail: stefano.fabbri@geo.unibe.ch, flavio.anselmetti@geo.unibe.ch
} 
Keywords Ambient vibrations · OBS · Clock error · Misorientation · Phase-velocity

\section{Introduction}

As part of the initiative to assess the hazard of earthquake-induced tsunamis at Lake Lucerne (Switzerland), an extensive Ocean Bottom Seismometer (OBS) campaign was carried out to measure seismic ambient vibrations (and earthquakes) on subaqueous slopes. Some of the selected subaqueous slopes for OBS array deployments are well-known to have failed in the past (Schnellmann et al., 2003; Hilbe et al., 2011; Hilbe and Anselmetti, 2015). Other slopes may have been weakened by previous seismic or aseismic loadings and could therefore fail spontaneously or in case of further external triggering mechanism such as an earthquake.

Common approaches for subaqueous slope-stability analysis include the multibeam bathymetry for geomorphometric studies, reflection seismic and geotechnical investigations (e.g. coring, cone penetration testing) to assess the sediment volume and the mechanical properties of the sediments that have failed or are susceptible to failure (e.g. Urgeles et al. 2006; Strasser et al. 2007; Sammartini et al. 2021). Controlled-source surface-waves surveys are also used to estimate the phase-velocity dispersion curve (DC) of the underwater subsurface sedimentary cover (Vanneste et al., 2011). However, depending on the stiffness of the sediments and the seismic source characteristics that is used in reflection seismics, or the sediment coring equipment, the investigation depth is generally limited to the first few meters of the subsurface.

Passive seismic measurements, on the other hand, provide data that can span a broader frequency range, therefore allowing us to investigate subaqueous slopes on a broad depth range. For example, single-station three-component methods (Nakamura, 1989; Bard, 1998; Bonnefoy-Claudet et al., 2006) allow us to estimate the resonance frequency of the submerged slope (Gomberg, 2018; Courboulex et al., 2020; Shynkarenko et al., 2021). Using OBS array measurements, the DC of propagating Love and Scholte waves can be estimated (Shynkarenko et al., 2021). In onshore environments, array methodologies (e.g. Aki 1957; Capon 1969; Poggi and Fäh 2010) and strategies combining different methodologies (e.g. Lontsi et al. 2016; Hobiger et al. 2021) have been presented for the estimation and interpretation of the surfacewaves phase-velocity dispersion curves on a broad frequency range. However, the DC estimation offshore presents additional challenges that include the determination of the precise location of the OBS on the lake floor, the estimation of the misorientation of the horizontal components with respect to the geographic north, also referred to as sensor orientation, and the clock error correction. Here, we present a detailed quantitative analysis of the preprocessing steps that were developed to process small aperture OBS array data from Lake Lucerne and that ultimately lead to obtain clear DC using the three-component High Resolution Frequency-Wavenumber (3C-HRFK; Poggi and Fäh 2010) and the Interferometric Multichannel Analysis of Surface Waves (IMASW; Lontsi et al. 2016) techniques. 


\section{Geological setting, site selection and instruments}

2.1 Geological setting of the lake and site selection

Lake Lucerne is a fjord-type lake situated in the perialpine region in central Switzerland. Figure 1 gives an overview of the lake, and the deployment locations for the OBS stations. The lake is characterized by an elongated shape between steep rock masses and the presence of moraine ridges between the different lake basins. A summary of the main geological and morphological features of the lake can be found in Hilbe et al. (2011). The predominant elongated shape of the glacially overdeepened Lake Lucerne basins is caused by the erosive power of the Reuss and Engelberg Glaciers and by the Brünig branch of the Aare Glacier during the Quaternary glaciations (Preusser et al., 2010). The present-day lake covers an area of $114 \mathrm{~km}^{2}$. The maximum water depth, in the Gersau Basin, is $214 \mathrm{~m}$ (e.g. Hilbe and Anselmetti, 2015). The lake contains Quaternary sediment covers that range from few meters to hundreds of meters (Finckh et al., 1984; Hilbe et al., 2011; Shynkarenko et al., 2021).

We selected 11 sites for OBS measurements within the lake that are (from west to east): Horw, St. Niklausen, Lucerne, Kehrsiten, Chrüztrichter, Weggis, Nase, Ennetbürgen, Chindli, Muota, and Flüelen (Figure 1). The selected slopes are characterized by relatively homogeneous and flat surface geomorphology and an undisturbed sediment cover.

\subsection{Instrumentation}

Two OBS types are used in the lake: the first type is called LOBSTER (Longterm Ocean Bottom SeismomeTER) and belongs to the DEPAS (German Instrument Pool for Amphibian Seismology), and the second type is called NAMMU and belongs to the Swiss Seismological Service at ETH Zurich. Both OBS types are equipped with popup buoy, bucket, rope, syntactic foam, releaser, hydrophone, batteries, datalogger, anchor, frame, and a self-level Trillium compact $120 \mathrm{~s}$ seismometer (see the annotated OBS in Fig. A.1, online resource). The NAMMU has a smaller size and weight than the LOBSTER (Table 1). In salty water, both instruments have the same effective weight (equivalent to an apparent mass of $30 \mathrm{~kg}$ ). The $3 \mathrm{C}$-seismometer of both the LOBSTER and the NAMMU uses the right-hand system such that if the vertical component "1" (or "Z") points up, the horizontal component "2" (or "X") and "3" (or "Y") are mutually orthogonal. A dual degree-of-freedom motorized gimbals and jam-free mechanical kinematic design preserves full seismometer performance. The gimbal system ensures that the vertical component is always vertical and orthogonal to the two mutually perpendicular horizontal components. In the presence of a slope gradient larger than 5 degrees, the component " 2 " points in the direction of maximum downslope. 


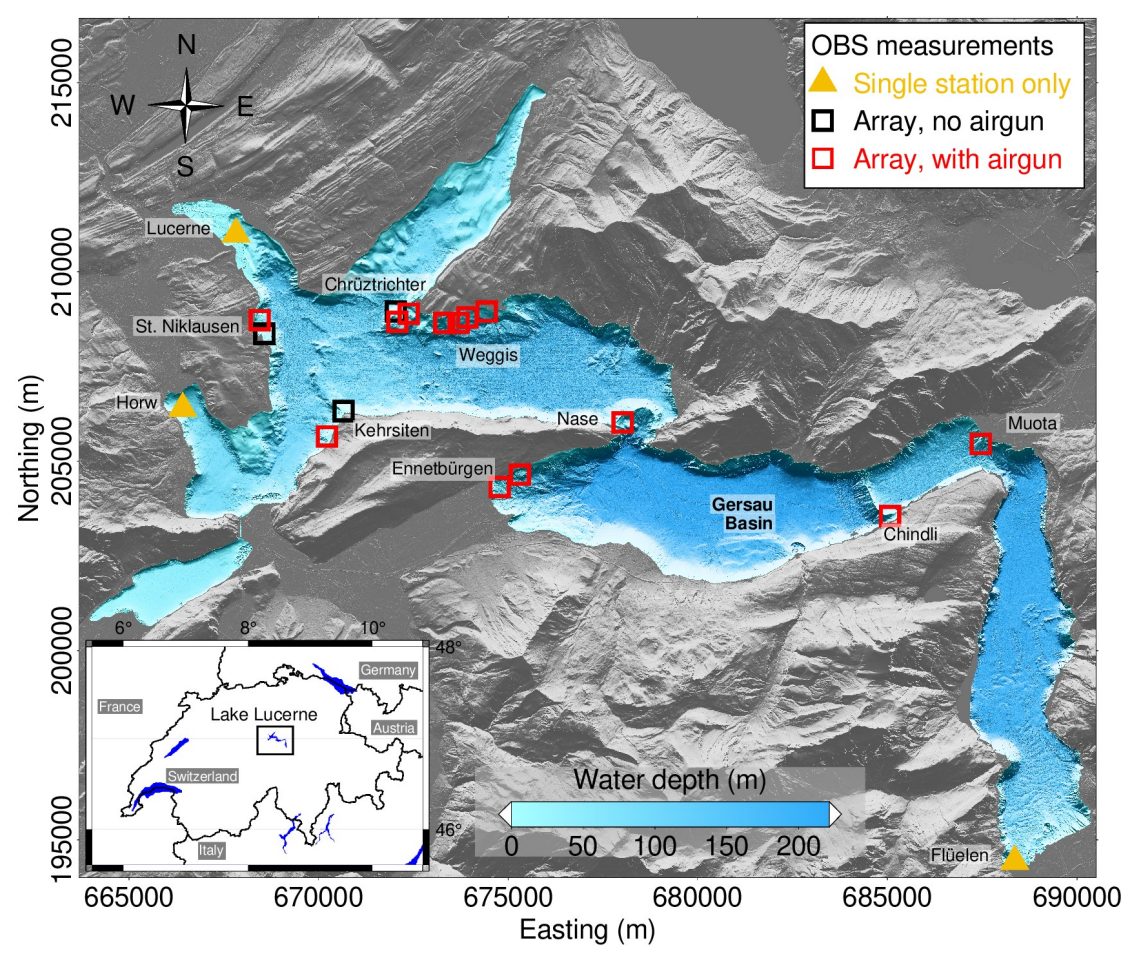

Fig. 1: OBS single station and array measurement sites in Lake Lucerne. The three triangle markers at Horw, Lucerne, and Flüelen indicate sites with OBS single station measurements only. The red and black square markers indicate OBS array measurements with and without additional airgun surveys, respectively. The coordinates are displayed using the Swiss Coordinate System LV03 in m. The background layers represent the topography around the lake (gray) and the bathymetry of Lake Lucerne. The inset indicates the location of Lake Lucerne within Switzerland (Source: Federal Office of Topography).

Table 1: Physical parameters of the LOBSTER and NAMMU OBS used in the lake.

\begin{tabular}{lll}
\hline Parameters & LOBSTER OBS & NAMMU OBS \\
\hline Approx. Volume $\left(\mathrm{mm}^{3}\right)$ & $1650 \times 1300 \times 720$ & $800 \times 600 \times 600$ \\
\hline Mass $(\mathrm{kg})$ & $\approx 300$ & $\approx 205$ \\
\hline Frame & $\begin{array}{l}\text { titanium, flexible } \\
\text { buoyancy from syntactic foam }\end{array}$ \\
\hline Data Logger & Seismic Data Logger "6D6" \\
\hline Releaser & K/MT 562 KUMQuat, titanium casing \\
\hline Hydrophone & HTI-04-PCA/ULF \\
\hline Seismometer & $\begin{array}{l}\text { Broadband Seismometer } \\
\text { Nanometrics "Trillium Compact 120 s" }\end{array}$ \\
\hline Anchor & Steel anchor \\
\hline
\end{tabular}




\section{OBS deployment and location procedures}

\subsection{OBS deployment}

The OBS stations were deployed on sites with relatively flat surface morphology. Prior to the intensive array campaign, we used the NAMMU to inspect the capability of the lake floor to accommodate the sensor for the long-term deployment, and to quality-check (e.g. noise level, frequency content) the recorded data. During this site-inspection phase, data were recorded at six different sites (Chrüztrichter, Ennetbürgen, Kehrsiten, St. Niklausen (x2), Weggis). Following our protocol, the OBS started the free descent on the lake floor only after a number of steps had been crosschecked. A communication between the OBS and the field laptop was established via a junction box called DIRK. From DIRK, a LAN or WLAN connection was established. Therefore, prior to the start of the recording, a web interface allowed us to check the recorder serial number, format the memory stick, set the number of recording channels, the sampling frequency, and synchronize the OBS clock with the GPS. In addition, the physical environmental conditions in the recorder casing such as the specific humidity, and the temperature were checked, as well as the battery voltage. After the recording was started, we checked that both the hydrophone and the three seismometer components record the seismic ambient noise on the platform. After this step, the acoustic releaser was disabled to ensure that the OBS does not respond to any incoming signal. On the platform, the screws of the seismometer and the coupling with the anchor were cross-checked and the OBS deployed. All OBS stations sampled the incoming signal at a rate of 250 samples per second.

The array geometry was designed to take full advantage of the nine available OBS while ensuring a good array resolution. The arrays consisted of three concentric rings with three stations each, where the OBS of each ring were deployed aiming at an equilateral triangle, resulting in a spiral arm configuration. The different rings were rotated by 30-35 degrees with respect to each other and the radii of consecutive rings had a ratio of 2.2-2.5. The maximum array aperture was chosen such that all stations were deployed on slopes with presumed homogeneous sediment cover. The station names of the array were set to have three characters and two digits. The first two characters were set to correspond to the first two initials of the surveyed site, or occasionally the first and the third initial when the previous setting was already used. The third character indicated same array configuration at the site. When applicable, the letters A, B, C, and D were used in that order as indicator for the first, second, third, and fourth configurations, respectively. In the particular case of a single station measurement only, the letter $\mathrm{S}$ was used. The last two-digit of the station name served as station identifier. Each array consisted of 9 OBS stations (8 LOBSTER and 1 NAMMU), except one array that consisted of 8 stations (7 LOBSTER and 1 NAMMU). The arrays St. Niklausen B (hereafter NIB), Chrüztrichter B (CHB), and Weggis B (WEB) were obtained from the previous array settings NIA, $\mathrm{CHA}$, and WEB by relocating the three OBS, most inner or outer stations, resulting in 6 co-located stations. In total, 17 arrays were performed. Table 2 gives a summary of the array measurement sites, a list of the array setups (A, B, C, D) with the corresponding minimum and maximum interstation distances, the minimum and maximum 
Table 2: Overview of array measurements. Arrays with * share six co-located stations with the previous array at the site.

\begin{tabular}{|c|c|c|c|c|c|c|c|}
\hline Site & $\begin{array}{l}\text { Array } \\
\text { name }\end{array}$ & $\begin{array}{l}\text { Inter-station } \\
\min -\max (\mathrm{m})\end{array}$ & $\begin{array}{l}\text { Water depth } \\
\text { min - max (m) }\end{array}$ & $\begin{array}{l}\text { Common start time } \\
\text { (UTC) }\end{array}$ & $\begin{array}{l}\text { Common end time } \\
\text { (UTC) }\end{array}$ & $\begin{array}{l}\text { Common duration } \\
\text { (dd hh mm ss) }\end{array}$ & $\begin{array}{l}\text { Airgun } \\
\text { shots nbr. }\end{array}$ \\
\hline \multirow{3}{*}{ Chrüztrichter } & $\mathrm{CHA}$ & $61.1-499.9$ & $21.5-37.5$ & 2018-05-08 09:46:12 & 2018-07-02 10:27:12 & $55 \mathrm{~d} 00 \mathrm{~h} \mathrm{41m} \mathrm{00s}$ & 0 \\
\hline & $\mathrm{CHB}^{*}$ & $21.8-199.8$ & $21.5-37.5$ & 2018-07-03 08:10:41 & 2018-07-05 07:36:49 & $1 \mathrm{~d} 23 \mathrm{~h} 26 \mathrm{~m} 08 \mathrm{~s}$ & 23 \\
\hline & $\mathrm{CHC}$ & $8.6-210.3$ & $32.8-39$ & 2019-08-20 11:03:23 & 2019-08-22 11:12:32 & 2d 00h 09m 09s & 139 \\
\hline Chindli & CIA & $11.3-177.6$ & $47.3-61.1$ & 2018-09-14 09:32:40 & 2018-09-17 08:15:48 & $2 \mathrm{~d} 22 \mathrm{~h} 43 \mathrm{~m} 08 \mathrm{~s}$ & 23 \\
\hline \multirow{2}{*}{ Ennetbürgen } & ENA & $12.6-152.5$ & $30.9-41.4$ & 2018-09-11 12:55:02 & 2018-09-13 07:55:19 & 1d 19h 00m 17s & 28 \\
\hline & ENB & $19.3-217.2$ & $19.2-42.8$ & 2019-06-27 09:39:23 & 2019-08-19 11:33:08 & $53 \mathrm{~d} 01 \mathrm{~h} 53 \mathrm{~m} \mathrm{45s}$ & 175 \\
\hline \multirow{2}{*}{ Kehrsiten } & KEA & $13.5-184.6$ & $5.1-21.5$ & 2018-07-06 10:44:53 & 2018-07-09 07:50:53 & $2 \mathrm{~d} 21 \mathrm{~h} 06 \mathrm{~m} \mathrm{00s}$ & 0 \\
\hline & KEB & $18.9-132.0$ & $8.5-23.6$ & 2019-08-23 09:32:22 & 2019-08-26 07:51:31 & $2 \mathrm{~d} 22 \mathrm{~h} 19 \mathrm{~m} \mathrm{09s}$ & 134 \\
\hline Muota & MUA & $32.4-124.1$ & $38.9-61.1$ & 2019-06-19 10:12:20 & 2019-06-24 10:08:15 & $4 \mathrm{~d} 23 \mathrm{~h} 55 \mathrm{~m} 55 \mathrm{~s}$ & 132 \\
\hline Nase & NAA & $28.5-229.8$ & $36.3-66.4$ & 2019-06-25 13:01:01 & 2019-06-26 08:24:00 & 0d 19h 22m 59s & 185 \\
\hline \multirow{3}{*}{ St. Niklausen } & NIA & $10.0-79.2$ & $18.5-25.9$ & 2018-05-02 08:42:19 & 2018-05-04 07:54:02 & $1 \mathrm{~d} 23 \mathrm{~h} 11 \mathrm{~m} \mathrm{43s}$ & 0 \\
\hline & $\mathrm{NIB}^{*}$ & $20.7-155.2$ & $18.5-30.5$ & 2018-05-04 10:02:00 & 2018-05-07 07:57:11 & $2 \mathrm{~d} 21 \mathrm{~h} 55 \mathrm{~m} 11 \mathrm{~s}$ & 0 \\
\hline & NIC & $19.6-168.2$ & $21.1-42.3$ & 2019-09-20 10:58:04 & 2019-09-23 08:07:49 & $2 \mathrm{~d} 21 \mathrm{~h} 09 \mathrm{~m} 45 \mathrm{~s}$ & 125 \\
\hline \multirow{4}{*}{ Weggis } & WEA & $11.7-228.2$ & $21.4-46$ & $2018-07-1008: 30: 55$ & 2018-07-12 07:20:58 & $1 \mathrm{~d} 22 \mathrm{~h} 50 \mathrm{~m} \mathrm{03s}$ & 29 \\
\hline & WEB* & $69.3-678.9$ & $17-81.3$ & 2018-07-12 11:00:15 & 2018-09-10 10:27:56 & $59 \mathrm{~d} 23 \mathrm{~h} 27 \mathrm{~m} \mathrm{41s}$ & $21,29,23$ \\
\hline & WEC & $15.7-216.4$ & $19.9-39.2$ & 2019-08-28 08:31:43 & 2019-09-16 11:58:21 & $19 \mathrm{~d} 03 \mathrm{~h} 26 \mathrm{~m} \mathrm{38s}$ & 96 \\
\hline & WED & $14.7-188.5$ & $22.5-47.9$ & 2019-09-17 09:39:23 & 2019-09-19 07:55:43 & $1 \mathrm{~d} 22 \mathrm{~h} 16 \mathrm{~m} 20 \mathrm{~s}$ & 175 \\
\hline
\end{tabular}

water depths, and the recording duration. For each array, the table also gives the start and end recording times. At 13 array locations, the OBS measurements were complemented with airgun surveys. The number of airgun shots per array, where available, is also given in Table 2. See Figure 1 for the OBS array locations. Data examples for the different preprocessing steps (location, misorientation and clock error correction) include OBS array measurements at Muota, Chüztrichter, and Ennetbürgen.

\subsection{OBS location procedure}

The coordinates of the OBS were measured at deployment with a dGPS. This position differs from the deployment location due to the drift of the boat and also differs from the final position of the instrument on the lake floor after the instrument has settled due to lake currents and boat-induced water movements. The coordinates at deployment were indicative for the post-deployment multibeam survey and interpretation.

Multibeam bathymetry data were acquired with a Kongsberg EM2040 echo sounder in a 1 degree by 1 degree beam-width configuration with a $300 \mathrm{kHz}$ operating frequency. Auxiliary sensors such as (i) a Seatex MRU5+ motion sensor for waveinduced motion compensation of the boat, (ii) a Trimble SPS361 heading sensor for the orientation and (iii) a Leica GX1230 GNSS receiver using the swiposGIS/GEO real-time kinematic for accurate positioning to 2-3 centimeters were used. A Valeport MiniSVS sound velocity sensor monitored permanently the sound speed close to the echo sounder. A vertical sound-velocity profile was recorded at the survey site with a Valeport MiniSVP probe to determine the refraction angles of the receiving acoustic lake-bottom reflections. The recorded raw data have been processed using the Caris HIPS/SIPS 9.1 software. During processing, all auxiliary sensor data were merged, 
reviewed, and manually corrected, if necessary. The point clouds were reviewed and different algorithms for rasterizations of the point clouds were tested. The resulting digital bathymetric map has a cell size of $0.5 \mathrm{~m}$ with a vertical accuracy of a few centimeters and holds detailed morphological information, allowing the identification of objects such as the OBS stations on the ground. Calculated backscatter data provide additional information on the hardness of the ground, therefore providing additional constraints for the identification of the OBS on the lake floor.

In the presence of noise or other morphological objects visible on the MB data (blocks, artifacts), pinpointing the OBS on the lake floor may not be straighforward. To tackle this issue, we ensured that, during the OBS recovery, the OBS recovery coordinates were measured with the dGPS when the rope associated with the popup buoy was stretched vertically. Figure 2 uses different geometrical symbols to indicate the OBS positions at different phases of the operation, i.e., deployment (dGPS), postdeployment (MB), recovery (dGPS). Examples of positions are shown for the OBS arrays at Chrüztrichter, Ennetbürgen, and Muota. At Chrüztrichter, the lake floor geomorphology is smooth. The combination of the OBS positions at different phases of the operation allowed us to pick the unique OBS location on the lake floor. At Ennetbürgen, the lake floor has a rough surface geomorphology, but here again the combination of the OBS position at different deployment to recovery phases allowed us to pick the unique OBS location on the lake floor. At Muota, strong scatterers are observed on the lake floor. In addition to the OBS position at different phases, the backscatter map shows the morphologic imprints of the OBS stations (e.g. Figure 2d for MUA). This information is used to pinpoint the correct OBS location. The OBS stations are visible and are slightly offset of the planned deployment and recovery coordinates.

Once the OBS are identified on the bathymetric map, the MB coordinates of the OBS are confidently considered as the most accurate, since the coordinates are neither affected by the post-deployment down-slope sliding of the OBS, nor biased by drifting of the OBS during deployment and recovery due to water currents. With this method, we achieve a location error in the range between 1.30 and $2.15 \mathrm{~m}$. The lower error bound corresponds to the maximum length of the NAMMU on the ground $(0.8 \mathrm{~m})$ augmented by the $\mathrm{MB}$ horizontal grid resolution $(0.5 \mathrm{~m})$ and the upper error bound corresponds to the maximum length of the LOBSTER location on the ground $(1.65 \mathrm{~m})$ augmented by the MB horizontal resolution. Figure 2 presents the OBS locations for the arrays $\mathrm{CHC}, \mathrm{ENB}$, and MUA at Chrüztrichter, Ennetbürgen, and Muota, respectively. Further location examples for St. Niklausen A (NIA), B (NIB) and C (NIC), Chrüztrichter A (CHA) and B (CHB), Kehrsiten A (KEA) and B (KEB), Weggis A (WEA), B (WEB), C (WEC) and D (WED), Nase A (NAA), Ennetbuergen A (ENA), and Chindli A (CIA) are shown in online resource Fig. B.1. 

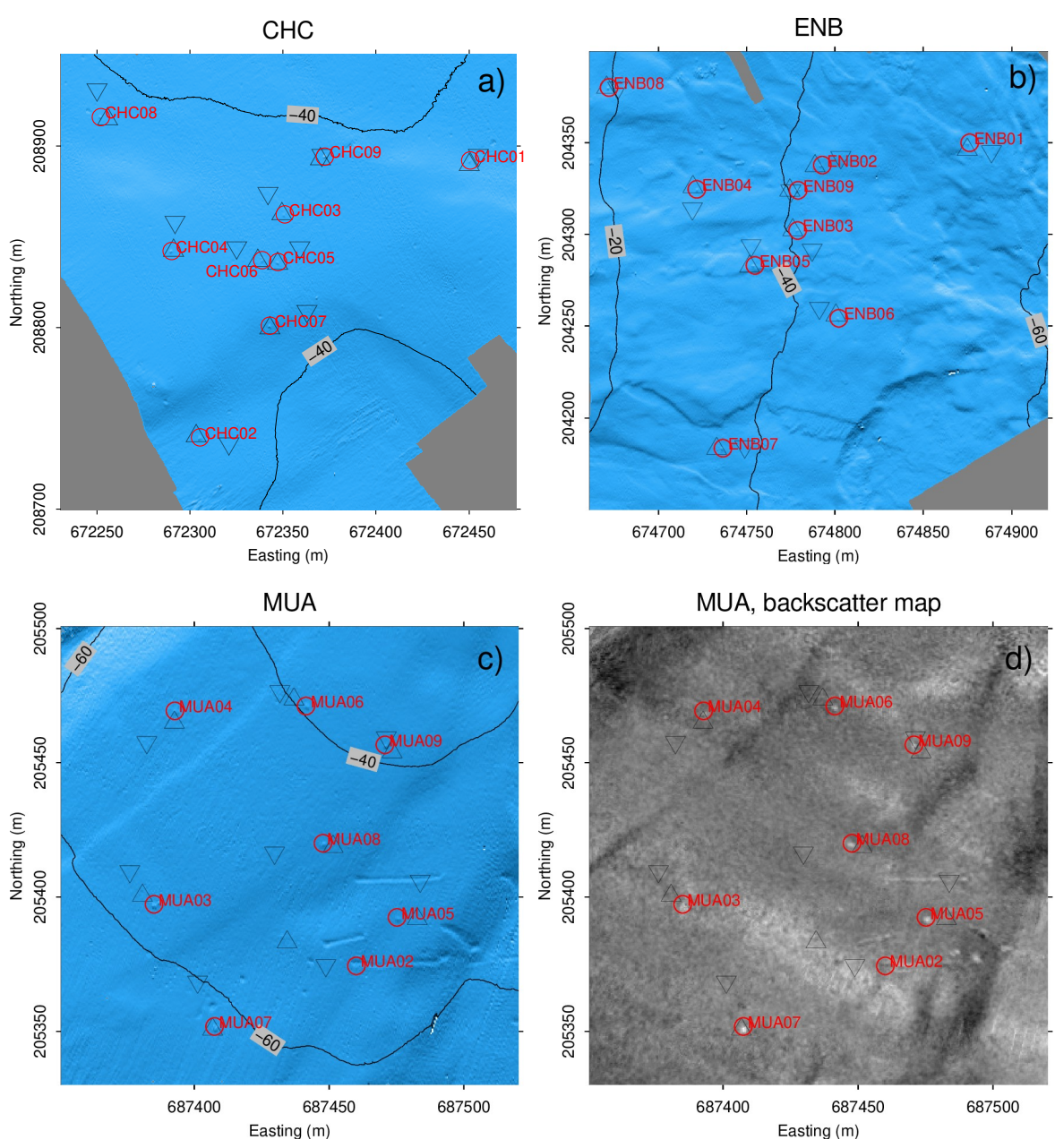

Fig. 2: Multibeam Bathymetric map at: a) Chrüztrichter array $\mathrm{C}(\mathrm{CHC})$; b) Ennetbürgen array B (ENB); c) Muota array A (MUA). The cell size is $0.5 \mathrm{~m}$ for OBS identification. Picked MB coordinates (circles), as well as the deployment (reverse triangles) and recovery coordinates (triangles) are indicated. d) Backscatter map at MUA.

\section{Airgun acquisition: Misorientation and clock error correction}

\subsection{Airgun acquisition}

Most OBS measurements are complemented by an extensive airgun survey prior to the OBS recovery from the lake floor. The purpose of the airgun survey is twofold: the estimation of the misorientation of the OBS horizontal components with respect to the north (Duennebier et al., 1987) and the estimation of the clock error of the OBS 
with respect to a selected station of the array. The operated airgun equipment is an electromechanical system with a $16.39 \mathrm{ml}\left(1 \mathrm{in}^{3}\right)$ air chamber operated at a pressure between 7 and $8 \mathrm{MPa}$. The airgun was lowered in the lake about $1 \mathrm{~m}$ below the water surface. It was trailed and set to release the compressed air every 18 seconds. This time between airgun shots was sufficiently long to ensure that the coordinates of the shooting points can be manually measured with the differential GPS and to prepare for the next shooting point. Each shot time was stored by a Centaur datalogger connected to the GPS and specifically prepared for this purpose.

Figure 3 shows the OBS stations at $\mathrm{CHA}, \mathrm{CHB}$, and $\mathrm{CHC}$ with airgun shooting points on top of the arrays. The airgun configuration was sparser in the earlier campaign as shown for example by the airgun shooting path on top of CHA and CHB. As a consequence of the sparse airgun shot positions, the statistical interpretation of the mean OBS misorientation was difficult. The airgun shooting configuration was later optimized to ensure that we obtain a good azimuthal coverage around each OBS station in an offset sufficient to obtain a good signal-to-noise ratio on the OBS components. See Fig. 3 for an example of airgun shooting geometry at array CHC. Further examples of airgun shooting geometries can be found in online resource Fig. C.1.

With a dominant frequency of the airgun of about $1200 \mathrm{~Hz}$ and knowing that the recorder of the OBS operates at $250 \mathrm{~Hz}$, it is clear that the first signal detected by the OBS is is not the primary pulse, but the signal generated by the subsequent collapse of the air bubbles.

\subsection{OBS misorientation estimation using the airgun signal}

After the free-fall descent of the OBS in the lake, the east component orients itself in the direction of maximum down-going slope, if the slope gradient is larger than 5 degrees. Otherwise, it stays as it descended. As pointed out before, the gimbal system ensures that the vertical component is always oriented towards the true vertical. Figure 4 shows the schematic representation of the OBS horizontal components' misorientation on the lake floor.

We developed a semi-automatic procedure called obsmis (OBS MISorientation) that exploits the signal generated by the airgun to estimate the misorientation of the OBS horizontal components. We search for the rotation angle maximizing the signal energy on the radial component, parallel to the direction of propagation of the airgun impulse, and at the same time minimizing the signal energy on the transverse component (see also Duennebier et al. 1987). Obsmis estimates the polarization of the airgun signal according to Jurkevics (1988). We define data windows of 12 samples with $90 \%$ overlap. The number of samples was selected to capture at most the first $\mathrm{P}$-wave arrival while reducing the contamination from the reflected and diffracted waves, and the time window overlap parameter was set to ensure a good visual inspection of the obsmis values with time after the airgun shot. The recorded airgun shot signal is high-pass filtered with a butterworth filter of order 3 , and corner frequency $5 \mathrm{~Hz}$. For each defined data window, the covariance matrix is calculated as 


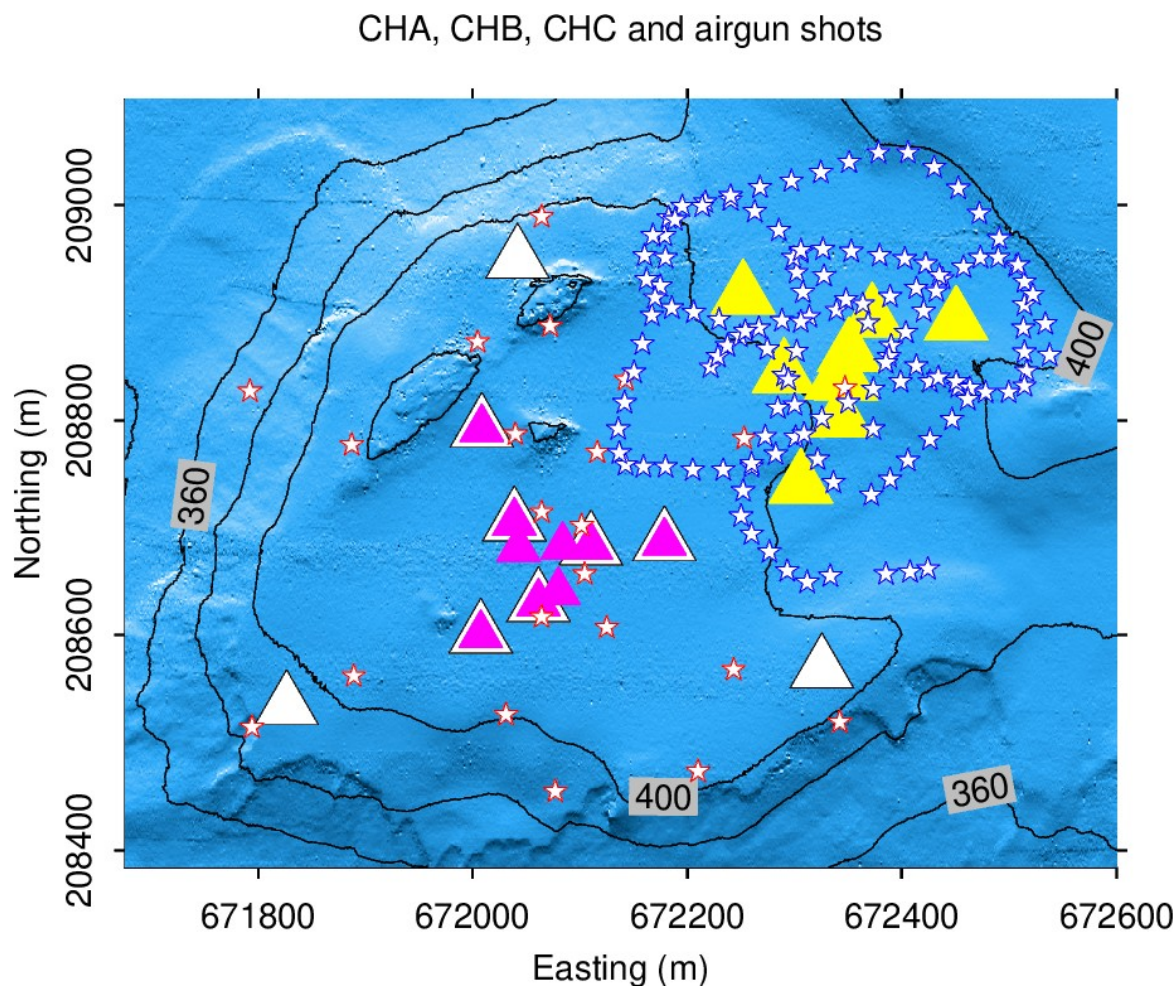

Fig. 3: Red stars indicate the airgun shooting path at CHA (white triangles) and CHB (magenta triangles). The blue stars indicate the airgun shooting path at $\mathrm{CHC}$ (yellow triangles). CHA and CHB have 6 co-located stations. The airgun path on top of CHA and CHB is a typical example of an airgun shot geometry with poor azimuthal coverage, especially for the outer stations. The airgun path on top of $\mathrm{CHC}$ is an example of good azimuthal coverage. The contour lines indicate the lake floor altitude. The lake surface is at $433 \mathrm{~m}$ above see level (masl). See online resource Fig. B.1 for more examples illustrating the airgun coverage.

$$
S=\left(\begin{array}{ccc}
\sum x^{2}(t) & \sum x(t) y(t) & \sum x(t) z(t) \\
\sum x(t) y(t) & \sum y^{2}(t) & \sum y(t) z(t) \\
\sum x(t) z(t) & \sum y(t) z(t) & \sum z^{2}(t)
\end{array}\right)
$$

where $x(t), y(t)$ and $z(t)$ are the signals of the eastern (direction of maximum downslope), northern and vertical components, respectively. The three eigenvalues of $S$ are linked with the three axes of the polarization ellipsoid. Therefore, the normalized eigenvectors $\mathbf{v}=\left(\begin{array}{c}v_{x} \\ v_{y} \\ v_{z}\end{array}\right)$ and $-\mathbf{v}$ are both associated with the largest eigenvalue of $S$ and indicate the direction of maximum polarization. The ambiguity between $\mathbf{v}$ and 


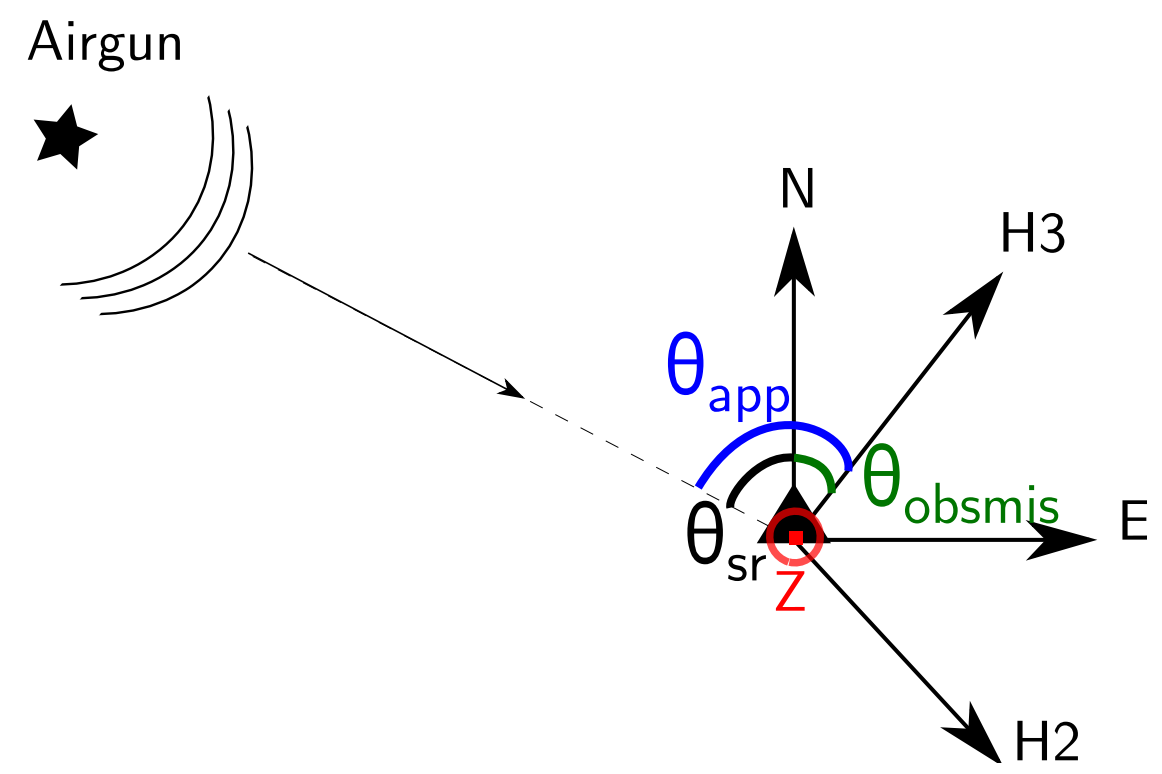

Fig. 4: Schematic representation of the OBS misorientation angle $\left(\theta_{\text {obsmis }}\right)$ of the OBS horizontal component on the lake floor. $\mathrm{N}$ and $\mathrm{E}$ indicate the geographic north and East, respectively. $\mathrm{H} 2$ and $\mathrm{H} 3$ are the horizontal components of the OBS. H2 points in the direction of maximum slope for a slope gradient larger than $5^{\circ}$. $\theta_{\text {app }}$ is the apparent azimuth, $\theta_{s r}$ is the source - receiver azimuth, and $\theta_{\text {obsmis }}$ is the OBS misorientation angle.

$-\mathbf{v}$ is solved based on the assumption of the airgun shot signal as a pure P-wave. The shot location at the water surface is always at higher elevation than the recording OBS at the lake bottom. Therefore, the $v_{z}$ component of the correct vector has to be positive and this vector is identified as the one pointing from the OBS to the airgun source. We can deduce the apparent azimuth $\theta_{a p p}$ and incident angle $\theta_{i n c}$ as $\theta_{a p p}=\arctan \left(\frac{v_{x}}{v_{y}}\right)$, if $v_{y}>0$ or $\theta_{a p p}=\arctan \left(\frac{v_{x}}{v_{y}}\right)+180^{\circ}$, if $v_{y}<0$, and $\theta_{i n c}=\arccos \left(v_{z}\right)$, respectively. Knowing the locations of the shot point and the OBS, we easily determine the sourcereceiver azimuth $\theta_{s r}$ of the signal for each shot and calculate the misorientation angle of the OBS from each moving window as $\theta_{\text {obsmis }}=\theta_{a p p}-\theta_{s r}$. It is then straightforward to manually pick the misorientation value from the moving time window values. Figure 5 shows a sample airgun signal recorded at the OBS station MUA09 of array $\mathrm{A}$ at Muota and presents the azimuthal coverage and the estimated misorientation value $\left(\theta_{\text {obsmis }}\right)$ at each azimuth, as well as the distribution of $\theta_{\text {obsmis }}$. The estimated $\theta_{\text {inc }}$ and $\theta_{\text {obsmis }}$ for each short time window are displayed. The incidence angle serves as quality measure to pick the appropriate $\theta_{\text {obsmis }}$ values, e.g., knowing the expected incidence angle, we can better isolate the part of the recorded signal which is related 
to the first arrival of the airgun signal, although this is not always trivial. The start of the $\theta_{\text {obsmis }}$ picking is marked by the vertical red line (Fig. $5 \mathrm{a}-\mathrm{c}$ ) and the samples which contributed to the statistical mean of $\theta_{\text {obsmis }}$ for this shot are marked as red dots (Fig. 5 c-d). The picking procedure is repeated for all shots and the variations of the $\theta_{\text {obsmis }}$ values with respect to the shot azimuth as well as the relative frequency of occurrence are given in Fig. 5 d-e. Using the picked $\theta_{\text {obsmis }}$ values from each shot, we estimate the mean orientation $\bar{\theta}_{\text {obsmis }}$ with 0 and $360^{\circ}$ and the corresponding standard deviation $\sigma$ using Equations (2) and (3) (see e.g. p.33, Fisher 1993).

$$
\begin{gathered}
\bar{\theta}_{\text {obsmis }}= \begin{cases}\arctan \left(\frac{X}{Y}\right) & \text { if } Y>0 \\
\arctan \left(\frac{X}{Y}\right)+180^{\circ} & \text { if } Y<0,\end{cases} \\
\sigma=\sqrt{(-2 \ln (R))},
\end{gathered}
$$

where $X=\sum_{i=1}^{N} \sin \left(\theta_{\text {obsmis }, i}\right), Y=\sum_{i=1}^{N} \cos \left(\theta_{\text {obsmis }, i}\right)$, and $R=\frac{1}{N} \sqrt{X^{2}+Y^{2}} \cdot i$ indicates the airgun shots and $N$ is the total number of airgun shots.

The slight azimuthal dependency of the estimates $\theta_{\text {obsmis }}$ on the shot azimuth can be related to the geomorphology of the site, as we work on slopes, or to the error associated with the airgun location (moving platform), or the error in the shot position associated with the resolution of the multibeam and the size of the OBS on the lake floor. The component misorientations for MUA are given in Figure 6. Detailed results presenting the variations $\theta_{\text {obsmis }}$ with respect to $\theta_{s r}$ and the corresponding histograms (similar to Figs. 5d-e and 6) for MUA as well as at CHB, CHC, CIA, ENA, ENB, KEB, NAA, NIC, WEB, WEC, and WED at each specific station are given in the online resource Figs. D.1. - D.12, respectively. The summary plot of the component misorientations is given in Fig. D13. The standard deviation of the estimated misorientation angle is about $10^{\circ}$, but can also be larger. These large standard deviation values can be understood as caused by the slight azimuthal dependence on the slope gradient of the lake floor morphology or error in OBS location and airgun shot positioning.

An important note is that, despite the solving of the $180^{\circ}$ ambiguity by using the upward-pointing eigenvector, the $180^{\circ}$ ambiguity is still observed for some sites. It can be caused by the complex nature of the analyzed time window signal, including for example reflections or refractions on interfaces at the lake bottom. In many cases, the ambiguity is solved using the bathymetry map and the direction of maximum down-going slope, if the slope gradient is larger than $5^{\circ}$, as the OBS orients itself in such a way that the $\mathrm{X}$ component points in the direction of maximum down-going slope.

\subsection{Clock error correction}

Starting from the clock error value measured at OBS recovery, a clock correction can be performed by assuming a linear clock-drift behavior (Hannemann et al., 2013; Hable et al., 2018). However, the clock can also drift nonlinearly (Gouédard et al., 

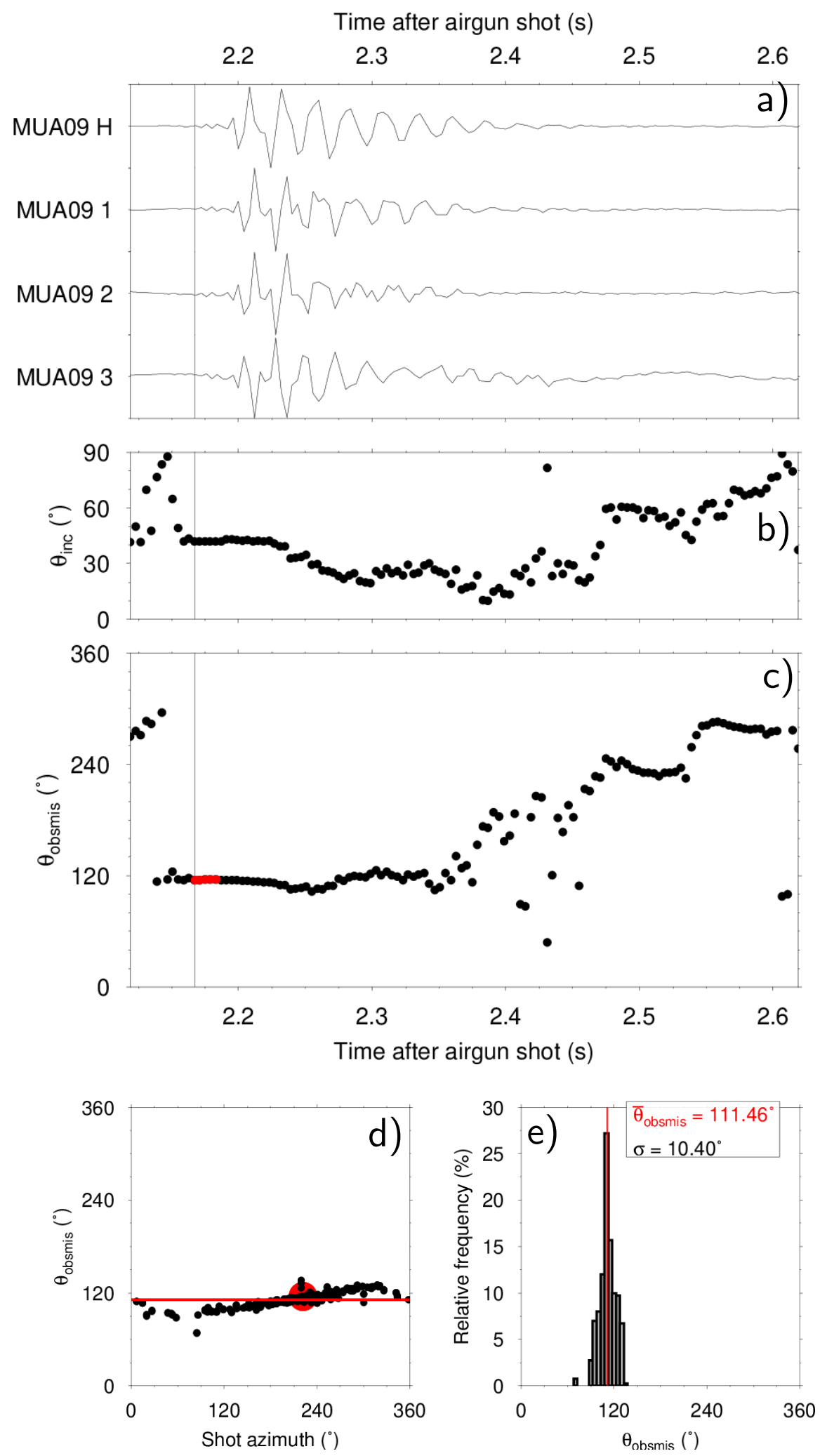

Fig. 5: a) Sample airgun shot recorded by the four components of OBS MUA09 at Muota. MUA09 H corresponds to the hydrophone component; MUA09 1, 2, and 3 correspond to the vertical $\mathrm{Z}, \mathrm{H} 2$, and $\mathrm{H} 3$ as shown in Figure 4, respectively. b) Variations of $\theta_{\text {inc }}$ with time. c) Variations of $\theta_{\text {obsmis }}$ with time. The vertical red line indicates the start of the picking of the apparent misorientation angle. d) Variations of $\theta_{\text {obsmis }}$ with respect to the airgun shot azimuth. The picked $\theta_{\text {obsmis }}$ values from the previous panel correspond to the large red dot. e) Histogram of the $\theta_{\text {obsmis }}$ values with a mean value $\left(\bar{\theta}_{\text {obsmis }}\right)$ of $(111.46 \pm 10.40)^{\circ}$. 


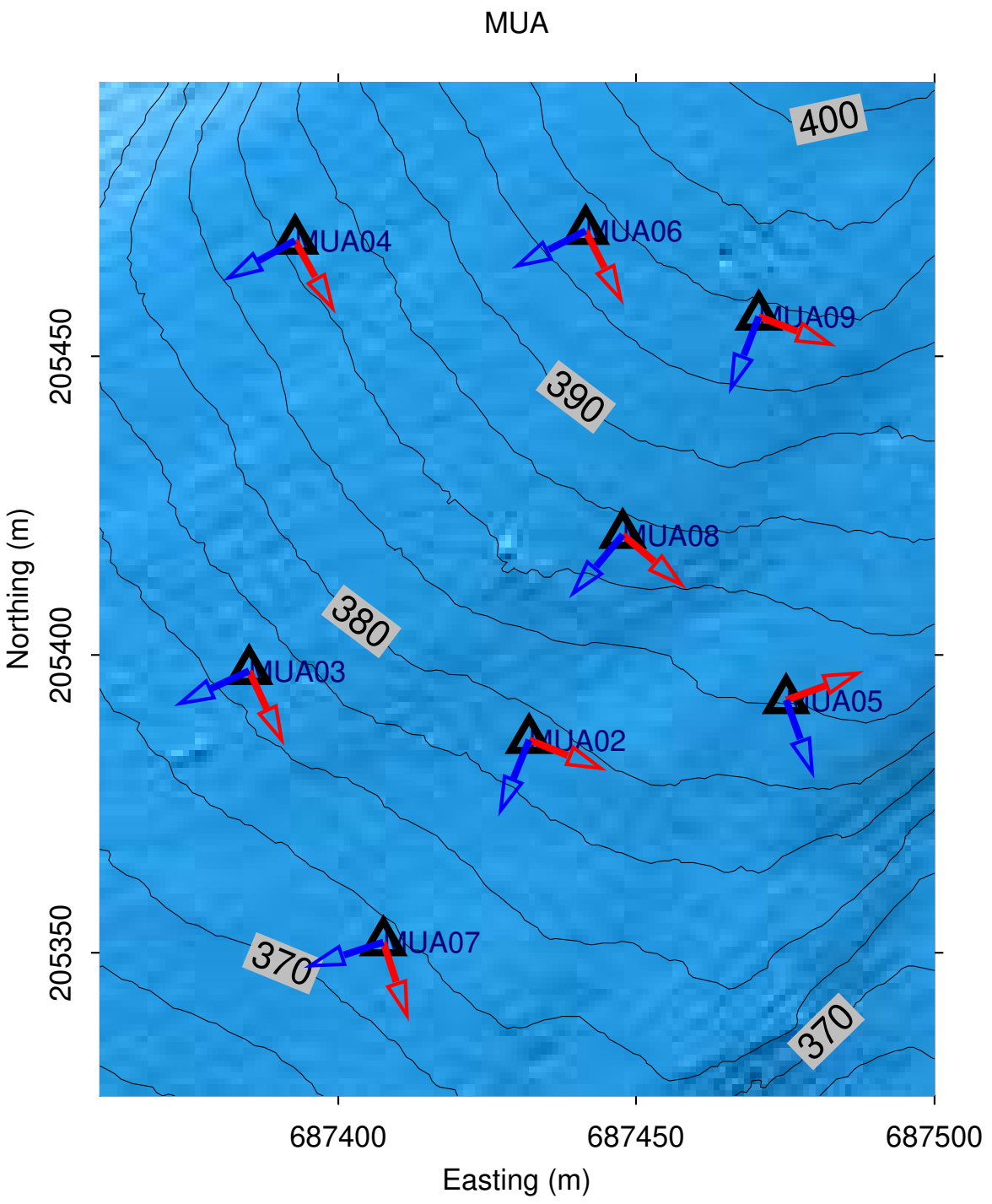

Fig. 6: Estimated sensor orientations for array MUA at Muota. The blue and red arrows respectively indicate the orientations of the $\mathrm{H} 2$ and $\mathrm{H} 3$ components. The OBS uses a right-hand system with the vertical component pointing upward as illustrated in Figure 4. 
Table 3: GPS and airgun estimated clock error for array B (CHB) at Chrüztrichter, respectively $\Delta T_{G P S}$ and $\Delta T_{\text {airgun }}$.

\begin{tabular}{lll}
\hline Station & $\Delta T_{G P S}(\mathrm{~s})$ & $\Delta T_{\text {airgun }} \pm$ std $(\mathrm{s})$ \\
\hline CHB01 & -0.7806 & $-0.7816 \pm 0.0205$ \\
CHB02 & -1.8702 & $-1.8685 \pm 0.0394$ \\
CHB03 & -2.3265 & $-2.3206 \pm 0.0252$ \\
CHB04 & -3.2870 & $-3.2591 \pm 0.0140$ \\
CHB05 & -2.5900 & $-2.5858 \pm 0.0276$ \\
CHB06 & -2.7665 & $-2.7687 \pm 0.0259$ \\
CHB07 & -2.5701 & $-2.5606 \pm 0.0301$ \\
CHB08 & -0.0668 & $-0.0668 \pm 0$ (Ref. station) \\
CHB09 & -0.3243 & $-0.3095 \pm 0.0345$ \\
\hline
\end{tabular}

2014). Here, we assumed that the absolute clock error measured at recovery when the recorder and GPS are synchronized is representative for the OBS station, independently of the linear or non-linear clock-drift behavior. The assumption holds for short-term measurements, and changes within the last two hours prior to OBS recovery can be neglected. This assumption allows us to shift the recordings with the respective clock error.

Alternatively to the clock error measured at the recovery of the OBS, we also used the airgun signal to estimate the relative clock error. The relevance of the airgun to estimate the clock error is two-fold: the clock error at some stations is non-linear and some arrays have co-located OBS stations with other arrays. In this case, the clock error of the stations that remain on the lake floor cannot be measured until they are recovered. A linear optimization process is able to find the clock error that minimizes the travel time difference with respect to a reference station. An example that uses airgun shots for clock correction is shown in Figure 7. It shows the example of array $\mathrm{B}(\mathrm{CHB})$ at Chrüztrichter. The choice for $\mathrm{CHB}$ is motivated by the fact that some OBS stations of the array exhibited large clock error. CHB was obtained from CHA by changing the location of three OBS stations. CHA operated since May $8^{\text {th }}, 2018$. CHB was deployed from July $3^{r d}, 2018$ 08:10:41 to July $5^{r d}, 2018$ 07:36:49 UTC. Six co-located OBS stations at CHB were recording from May $8^{\text {th }}, 2018$ 09:46:12 UTC. The airgun shot experiment took place on July $4^{\text {th }}$, 2018. In Figure 7, the green signals show the raw traces and the black curves the ones after time correction. All stations are time-corrected with respect to the OBS station CHB08 that had the lowest clock error at recovery. Table 3 gives the measured clock error at the OBS recovery $\left(\Delta T_{G P S}\right)$, and the clock error estimated from the airgun shots $\left(\Delta T_{\text {airgun }}\right)$. The clock error ranges from -3.287 to $-1.8685 \mathrm{~s}$ for the two-month recording period. These variations are very large as we expected a variation in the order of $0.1 \mathrm{~s}$ for a clock timing accuracy of $0.02 \mathrm{ppm}$.

After changing the recorders of the OBS in September 2018, the clock error of the measurements significantly improved. Also, the error was of the same order as the expected airgun-based time shift estimates. For this reason, for the array measurements with changed recorders, the time correction was performed by using the clock error at recovery. 

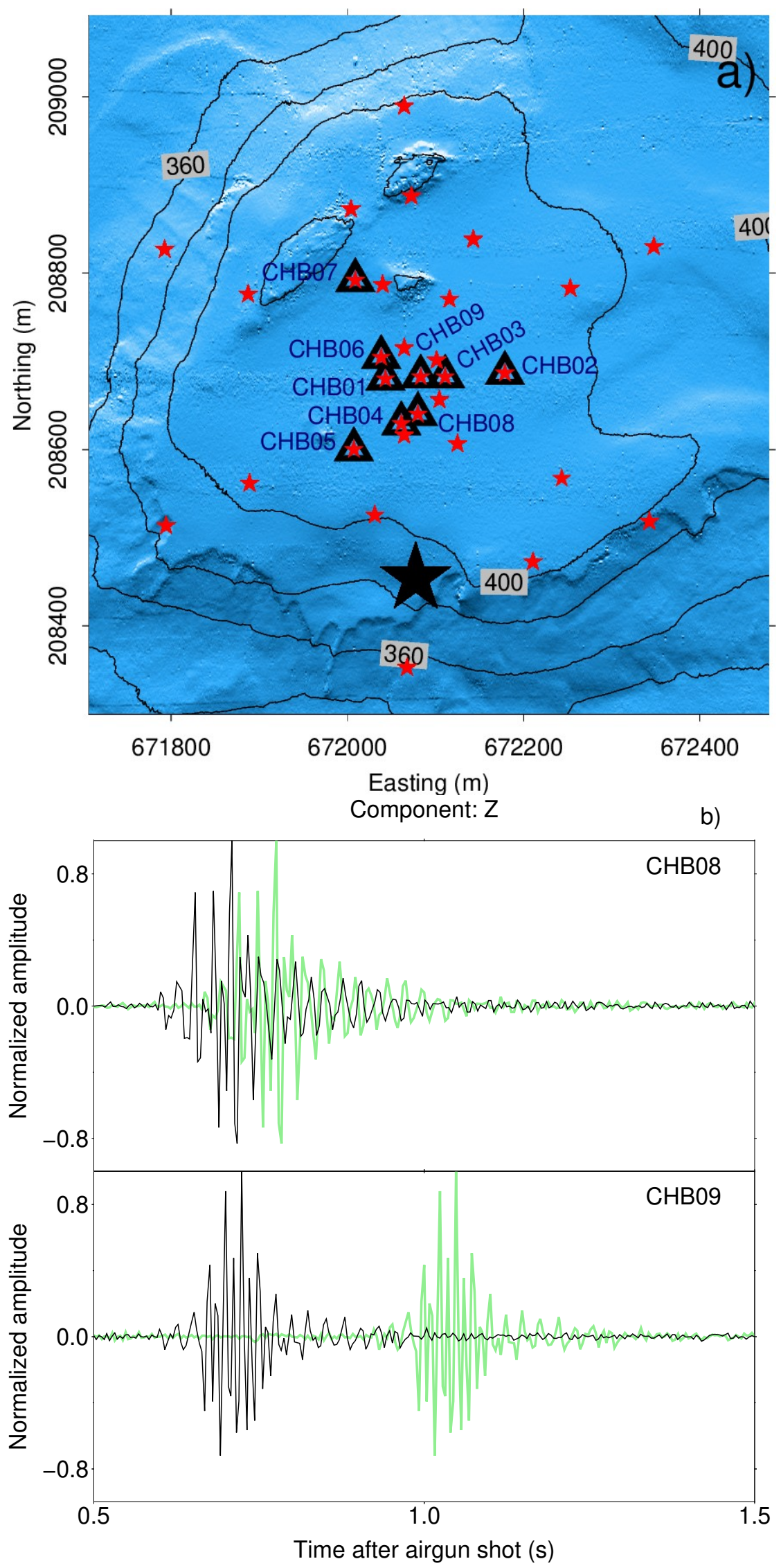

Fig. 7: a) Final array configuration on the lake floor (black triangles) for CHB. The red stars indicate the airgun shot locations. The large star marker indicates the airgun shot position for which we present the corrected and uncorrected signals. b) Uncorrected traces are shown in light green color and clock error corrected traces are shown in black for the reference station CHB08 and the station CHB09. Measured and airgunestimated clock errors are given in Table 3. Each trace is normalized to its maximum amplitude. 
Table 4: Clock error, misorientation angles $\left(\bar{\theta}_{\text {obsmis }}\right)$ and OBS coordinates for the stations of the array MUA. Coordinates are measured using two techniques: dGPS and multibeam (MB); the difference in OBS locations provided by both techniques is given in the last column $(\Delta d)$.

\begin{tabular}{|c|c|c|c|c|c|c|c|c|c|}
\hline \multirow{2}{*}{ OBS name } & \multirow{2}{*}{$\begin{array}{l}\Delta T_{G P S} \\
\text { (s) }\end{array}$} & \multirow{2}{*}{$\begin{array}{l}\bar{\theta}_{\text {obsmis }} \\
\left(^{\circ}\right)\end{array}$} & \multicolumn{3}{|c|}{ Coordinates using dGPS (m) } & \multicolumn{3}{|c|}{ Coordinates using MB (m) } & \multirow{2}{*}{$\Delta d(\mathrm{~m})$} \\
\hline & & & CH_X & $\mathrm{CH}_{-} \mathrm{Y}$ & $\mathrm{CH} Z \mathrm{Z}$ & $\mathrm{CH}_{-} \mathrm{X}$ & $\mathrm{CH}_{-} \mathrm{Y}$ & $\mathrm{CHZ}$ & \\
\hline MUA02 & 0.063 & $113 \pm 18$ & 687434.48 & 205383.32 & 378.9 & 687432.07 & 205385.76 & 378.9 & 3.43 \\
\hline MUA03 & 0.017 & $147 \pm 25$ & 687380.73 & 205400.66 & 375.8 & 687385.11 & 205397.33 & 376.2 & 5.52 \\
\hline MUA04 & 0.044 & $150 \pm 10$ & 687392.66 & 205465.10 & 384.7 & 687392.78 & 205469.42 & 385.4 & 4.38 \\
\hline MUA05 & 0.012 & $72 \pm 23$ & 687482.65 & 205391.89 & 382.8 & 687475.06 & 205392.42 & 382.4 & 7.62 \\
\hline MUA06 & -0.209 & $148 \pm 25$ & 687436.88 & 205473.76 & 393.8 & 687441.47 & 205471.09 & 393.9 & 5.31 \\
\hline MUA07 & 0.052 & $163 \pm 27$ & 687406.79 & 205350.86 & 371.7 & 687407.53 & 205351.75 & 371.9 & 1.19 \\
\hline MUA08 & -0.009 & $127 \pm 19$ & 687451.51 & 205418.77 & 386.6 & 687447.69 & 205420.09 & 386.8 & 4.04 \\
\hline MUA09 & 0.040 & $111 \pm 10$ & 687473.39 & 205454.02 & 394.1 & 687470.57 & 205456.66 & 394.6 & 3.90 \\
\hline
\end{tabular}

\section{Data processing: extraction of Scholte and Love waves phase-velocity dispersion curves}

Two array processing techniques are used to estimate the phase velocity dispersion curves with the array data measured at Muota. The first approach is the threecomponent High Resolution Frequency-Wavenumber technique for both Scholte and Love waves DC extraction (Poggi and Fäh, 2010). The second approach is the Interferometric Multichannel Analysis of Surface Waves for Scholte waves DC extraction (Lontsi et al., 2016).

\subsection{High resolution frequency-wavenumber approach}

Figure 8 presents an example of phase-velocity dispersion curves extracted from the array at Muota (MUA) before (raw data) and after location, time and misorientation correction of the data (preprocessed data). For the analysis, we selected a twohour window of the recorded data on the day of OBS recovery. The locations of the OBS stations for the raw data are obtained using dGPS at recovery. For the raw data, no orientation and clock error are corrected. For the pre-processed data, we apply a multi-step correction procedure: first, we replace the dGPS coordinates with the multibeam (MB) coordinates; then, we make a clock correction by shifting the traces by the clock error value and assuming a constant clock error for each station during the analyzed time window; the last step is the misorientation correction. The $\bar{\theta}_{\text {obsmis }}$ estimates for OBS stations at Muota are given in Table 4 and Figure 6. Table 4 further gives the clock error measured at recovery $\left(\Delta T_{G P S}\right)$, the coordinates of the OBS stations measured with the dGPS and with the multibeam bathymetry, and also the variation in terms of distance between the two measured positions. Here we use the clock error measured at recovery because their values are in the same order as the error of the clock error estimates obtained with the airgun procedure.

For the data analysis and extraction of Scholte and Love waves phase-velocity dispersion curves (Figure 8), we apply here the 3C-HRFK method (Poggi and Fäh, 
2010). As expected, there is no clear sign and shape of the dispersion curves in case of uncorrected data, even for the vertical component, where only the time and location corrections are important. For the corrected recordings, we observe very clear and well-resolved dispersion curves on the transverse and vertical components, which provide information about the velocities of Love and Scholte waves, respectively. We also observe an improved result on the radial component that is relevant for Scholte waves.

\subsection{Interferometric Multichannel Analysis of Surface Waves}

The advantages of active shot experiments with known source location and passive microtremor recordings are combined by using, in a first step, the interferometric principle (Snieder, 2004; Curtis et al., 2006; Schuster, 2009; Wapenaar et al., 2010) to estimate the correlation functions for the vertical components of the distinct receiver pairs. The resulting correlograms, assuming the equivalence between the inter-station cross-correlation time-derivative pair and the Green's function are re-ordered according to the respective inter-station distance to build a virtual active experiment setup (Figure 9). We then apply, in a second step, the Multichannel Analysis of Surface Waves (MASW) method to extract the phase velocity dispersion curve of Scholte waves (Lontsi et al., 2016). Figure 9 (bottom) shows the phase-velocity dispersion. The dispersion characteristic of the Scholte waves is identified and manually picked in the frequency range between 2.1 and $3.2 \mathrm{~Hz}$. The DC for Scholte waves obtained using the HRFK is overlaid for comparison.

\section{Discussion}

Processing the OBS data for the estimation of the phase velocity dispersion curve requires additional steps to be considered in the data preparation phase that are usually not part of the processing procedure of onshore data (Fig. 10).

The first step is the localization of the OBS on the lake floor. We have shown that by using a combination of the multibeam bathymetry, the backscatter map, and the differential GPS data at deployment and recovery, we can uniquely identify the position of the OBS on the lake floor with an uncertainty of $1.3 \mathrm{~m}$ for the NAMMU and $2.15 \mathrm{~m}$ for the LOBSTER. These uncertainty values correspond to the maximum length of the OBS on the lake floor added to the multibeam grid resolution of $0.5 \mathrm{~m}$. The location procedure is optimized for shallow water environments and is technically limited in deep water environments by the maximum rope length that the bucket associated with the OBS can accommodate. An additional factor affecting the measurement of the OBS position at recovery is the presence of water currents, or the drift of the boat. It can therefore be difficult to have the rope in a vertical position. Nevertheless, dGPS measurements are used to aid in the interpretation of the multibeam measurement. As a consequence of the uncertainties on the position, seismic waves with wavelengths below $4.3 \mathrm{~m}$ cannot be resolved. 

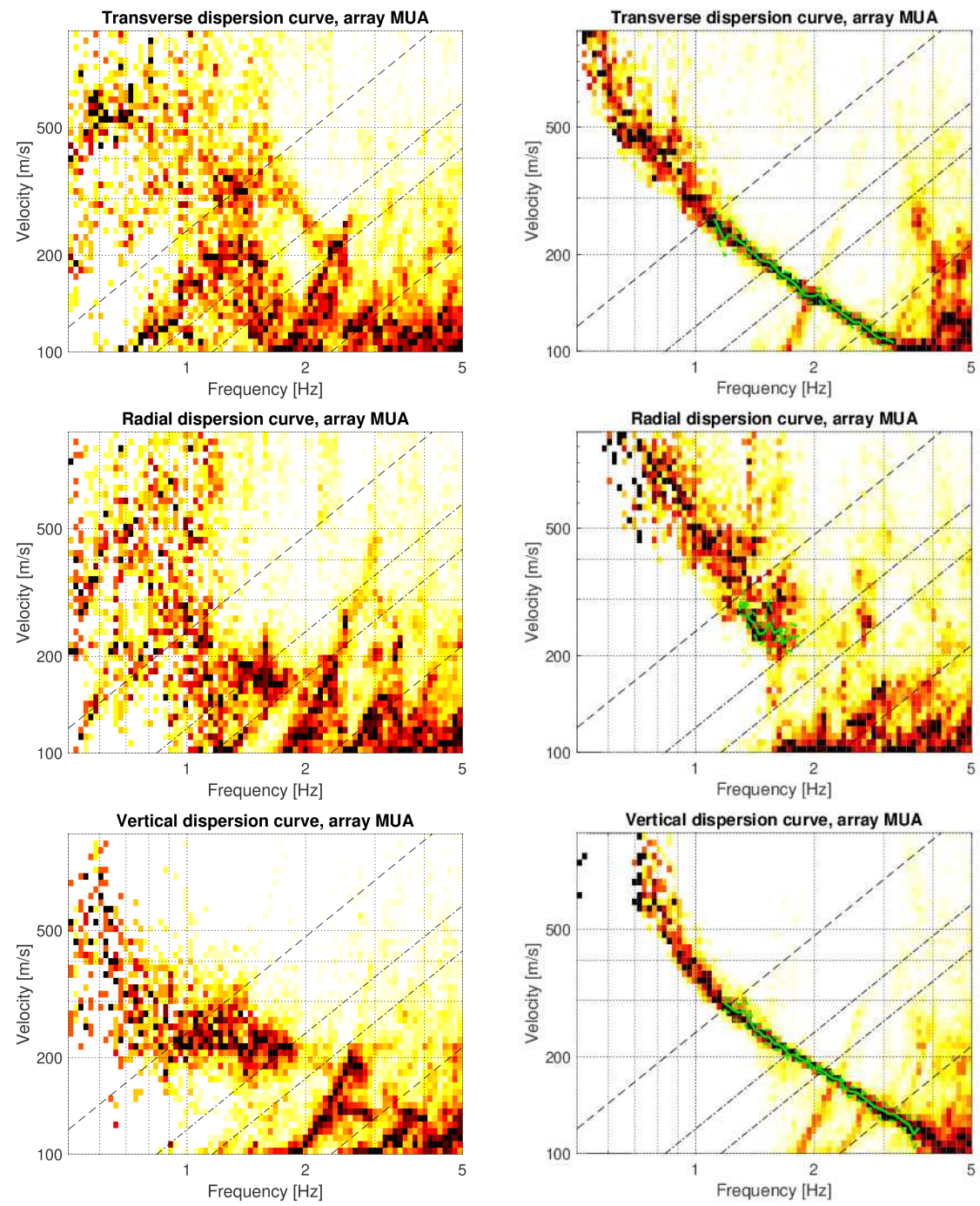

Fig. 8: Phase velocity dispersion curves at Muota. Left panel: without preprocessing steps. Right panel: with consideration of the three preprocessing steps (position, orientation, clock error). The dashed and dashed-dotted black lines are the array resolution limits. The green lines indicated the phase-velocity dispersion curves that were picked.

We addressed the challenges related to orientation by using airgun data. In the absence of airgun signal, methods based on earthquakes (Stachnik et al. 2012; Doran and Laske 2017) or correlation Green's functions (Zha et al., 2013) can be used. While earthquake-based polarization analysis may suffer a limited azimuthal coverage especially at the areas of low-to-moderate seismicity or when the seismicity is 

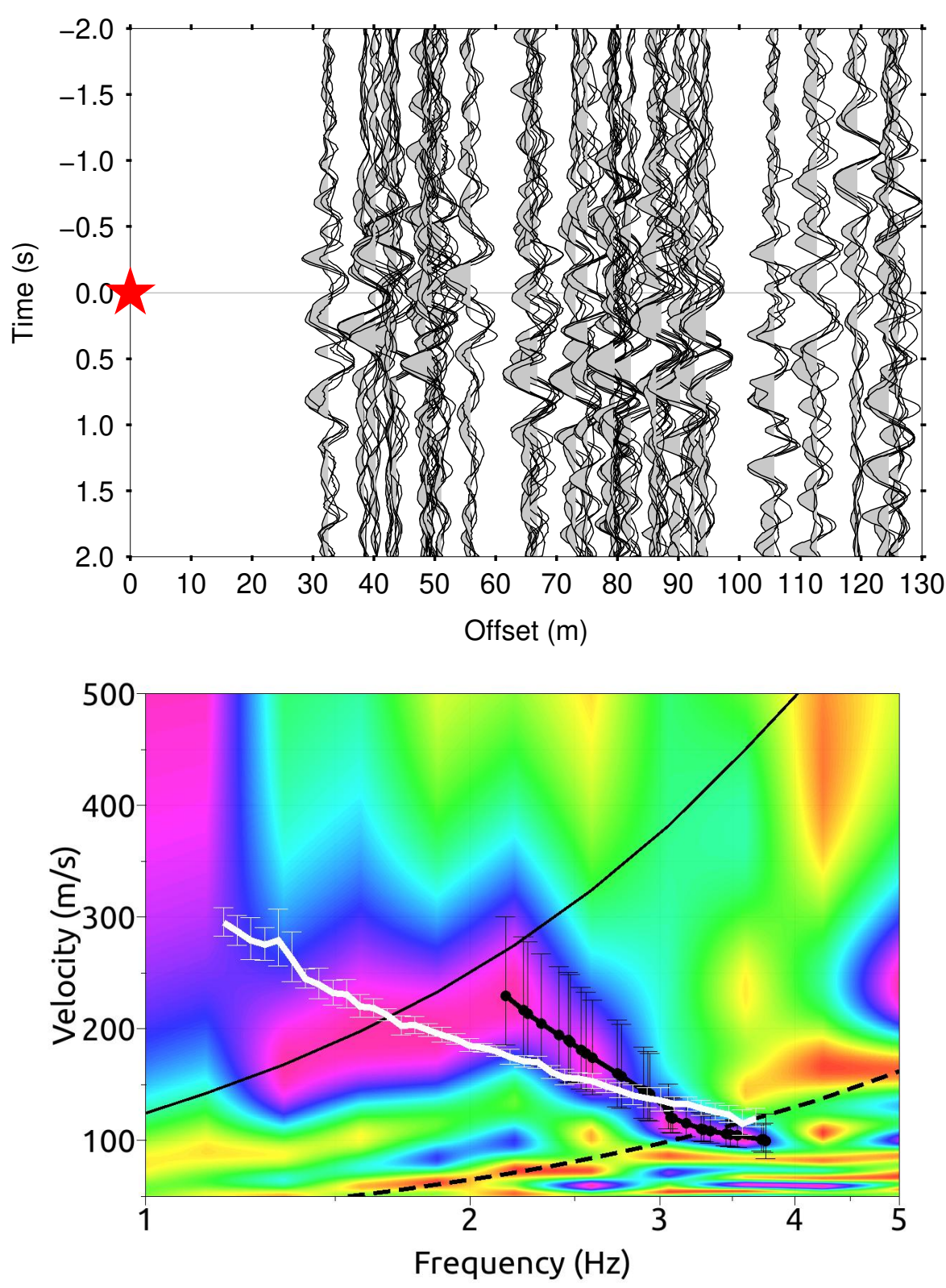

Fig. 9: Top: Resulting cross-correlation Green's functions from all receiver pair combinations (See array setup for Muota in Figure 3). The red star represents the virtual source. Bottom: Scholte wave phase-velocity dispersion curve map from the virtual array set-up. A phase-velocity dispersion branch of Scholte waves in black is observed and manually picked between 2 and $4 \mathrm{~Hz}$. The continuous and dashed black curves define the virtual array resolution limits. The continuous curve is linked to the maximum analyzed inter-station distance and to the dashed curves is linked to the offset between the virtual source and the first receiver. The white curve corresponds to the picked Scholte waves phase velocity from the HRFK (Figure 8). 
azimuth band-limited. Airgun-based polarization analysis has shown to be very efficient in this study.

We retrieved the misorientation of the sensor with a $180^{\circ}$ ambiguity at many sites. The reason why we still observe the ambiguity lies in the analyzed data. The sampling rate is $250 \mathrm{~Hz}$ and the dominant frequency of the airgun signal is about 1200 $\mathrm{Hz}$. With this limitation, the analyzed window does not contain pure direct P-wave. As a consequence, obsmis estimates may show the ambiguity. MUA is a very good example of $\bar{\theta}_{\text {obsmis }}$ representation in $0-360^{\circ}$ without ambiguity. The remaining arrays are shown in online resource Figs. D1.1 to D.11. With the sampling frequency limitation mentioned above, it is also expected that MUA shows the ambiguity for some shot azimuths, but this is not the case. This is probably related to the maximum shot-receiver distance that was analyzed and indicates that a criteria may be set to define a critical shot-receiver distance to minimize the effects of diffracted and reflected waves. This scenario was not investigated. Instead, we took the advantage of the existing bathymetry data and the default sensor orientation to address the ambiguity issue. The direction of maximum slope was used because the instrument is constructed in a way that, for slope angles larger than $5^{\circ}$, the east component of the OBS orients itself to the direction of maximum down-going slope. As most of the stations were on slopes, addressing the ambiguity was relatively straightforward. Applying the preprocessing above, clear Scholte and Love waves phase-velocity dispersion curve branches were retrieved using two array methods, the 3C-HRFK and the IMASW. The comparison of the picked phase-velocity dispersion curves for the Scholte waves shows that within the error range the DC are comparable in the frequency range above $3 \mathrm{~Hz}$. A clear difference is observed for frequency below $3 \mathrm{~Hz}$. This difference can be associated with the basic assumption behind the two methods, i.e. 2D wavefield propagation for the 3C-HRFK and the unidirectional wavefield propagation assumption for the IMASW. Further applications of the current workflow for phase-velocity dispersion curve estimation and their inversion for the subsurface structure are given in Shynkarenko et al. (2021).

\section{Conclusion}

As part of the initiative to assess the causes, control and mechanisms of mass-movement triggered tsunamis in lakes, we presented the workflow used to efficiently estimate the phase-velocity dispersion curves of Scholte and Love waves from small aperture OBS ambient-vibration array data. The workflow involves three main steps. In the first step, a multibeam bathymetric (MB) survey is performed on top of each array to locate, with a precision up to the size of the OBS plus the MB grid resolution, the OBS locations on the lake floor. In the second and third steps, the airgun data are used to estimate the OBS misorientation and to correct the clock error. For arrays that present an ambiguity, each station was regarded individually especially when $\bar{\theta}_{\text {obsmis }}$ does not correspond to the mean of any predominant distribution. By applying all steps to the recorded data, we successfully obtained a clear phase-velocity dispersion curve for both Scholte and Love waves. 
Site selection

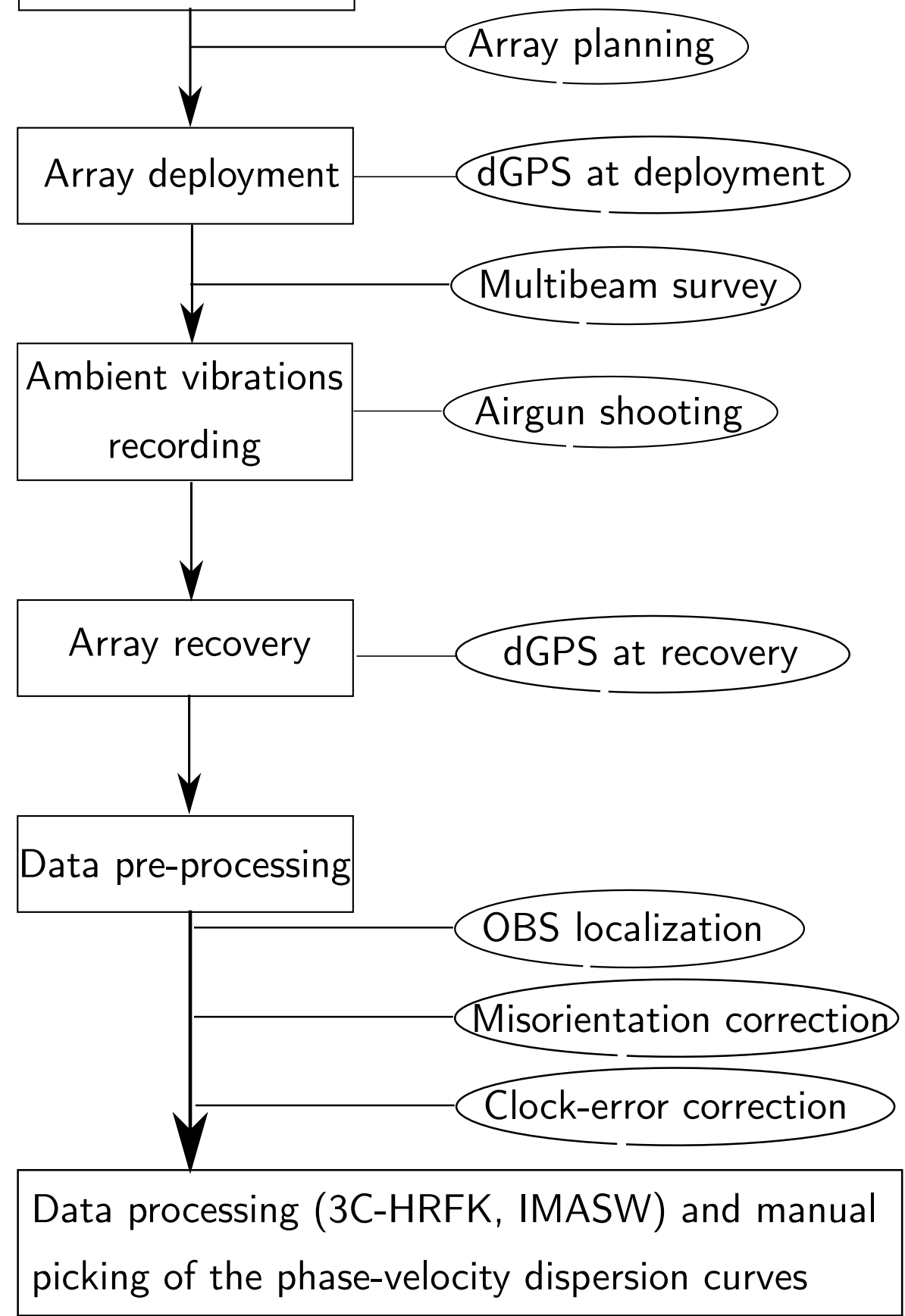

Fig. 10: Schematic representation of workflow for phase-velocity dispersion curve estimation using OBS data. 


\section{Funding}

This research work is funded through the Sinergia program of the Swiss National Science Foundation (SNSF) under grant number 171017.

\section{Conflicts of interest/Competing interests}

The authors declare no conflicts of interest.

\section{Availability of data and material}

The OBS data are archived at ETHZ. Any data request should be addressed to the authors.

\section{Code availability}

obsmis, 3C-HRFK, and IMASW are available from the authors.

Acknowledgements We thank the German Instrument Pool for Amphibian Seismology (DEPAS), hosted by the Alfred Wegener Institute in Bremerhaven, for providing the Ocean Bottom Seismometers. The airgun equipment is provided by the Department of Earth Sciences at the University of Geneva, Switzerland via Stéphanie Girardclos. We also thank all technicians, colleagues, and students who assisted during the deployment and recovery campaigns of the OBS: Dario Chieppa, Pascal Graf, Miroslav Hallo, Mauro Häusler, Lukas Heiniger, Michael Hilbe, Paulina Janusz, Ulrike Kleinbrod, Clotaire Michel, Francesco Panzera, Vincent Perron, Nora Schweizer, Michael Strupler, Franz Weber. Most of the figures were generated using generic mapping tools (Wessel et al., 2013).

\section{References}

Aki K (1957) Space and time spectra of stationary stochastic waves, with special reference to microtremors. Bull Earthq Res Inst 35:415-456

Bard PY (1998) Microtremor measurements: a tool for site effect estimation? Stateof-the-art paper. Effects of Surface Geology on Seismic Motion 3:1251-1279

Bonnefoy-Claudet S, Cornou C, Bard PY, Cotton F, Moczo P, Kristek J, Fäh D (2006) H/V ratio: a tool for site effects evaluation. Results from 1-D noise simulations. Geophysical Journal International 167(2):827-837, DOI 10.1111/j.1365-246X.2006.03154.x, URL http://gji.oxfordjournals.org/content/167/2/827.abstract, http://gji.oxfordjournals.org/content/167/2/827.full.pdf+html

Capon J (1969) High-resolution frequency-wavenumber spectrum analysis. Proc IEEE 57(8):1408-1419

Courboulex F, Mercerat ED, Deschamps A, Migeon S, Baques M, Larroque C, Rivet D, Hello Y (2020) Strong site effect revealed by a new broadband seismometer 
on the continental shelf offshore nice airport (southeastern france). Pure and Applied Geophysics 177(7):3205 - 3224, DOI 10.1007/s00024-019-02408-9, URL https ://doi .org/10.1007/s00024-019-02408-9

Curtis A, Gerstoft P, Sato H, Snieder R, Wapenaar K (2006) Seismic interferometry-turning noise into signal. The Leading Edge 25(9):1082-1092, DOI 10.1190/1.2349814, URL http://dx.doi.org/10.1190/1.2349814, http: //dx.doi.org/10.1190/1.2349814

Doran AK, Laske G (2017) Ocean-Bottom Seismometer Instrument Orientations via Automated Rayleigh-Wave Arrival-Angle Measurements. Bulletin of the Seismological Society of America 107(2):691-708, DOI 10.1785/0120160165, URL https://doi.org/10.1785/0120160165, https://pubs.geoscienceworld.org/bssa/article-pdf/107/2/691/ 3942531/BSSA-2016165.1.pdf

Duennebier FK, Anderson PN, Fryer GJ (1987) Azimuth determination of and from horizontal ocean bottom seismic sensors. Journal of Geophysical Research: Solid Earth 92(B5):3567-3572, DOI 10.1029/JB092iB05p03567, URL https://agupubs.onlinelibrary.wiley.com/doi/abs/10.1029/ JB092iB05p03567, https://agupubs.onlinelibrary.wiley.com/doi/ pdf/10.1029/JB092iB05p03567

Finckh P, Kelts K, Lambert A (1984) Seismic stratigraphy and bedrock forms in perialpine lakes. GSA Bulletin 95(9):1118-1128, DOI 10.1130/0016-7606(1984)95〈1118:SSABFI $\rangle 2.0 . C O ; 2, \quad$ URL https : //doi.org/10.1130/0016-7606 (1984)95<1118:SSABFI>2.0.C0;2, https://pubs.geoscienceworld.org/gsabulletin/article-pdf / 95/9/1118/3419566/i0016-7606-95-9-1118.pdf

Fisher NI (1993) Statistical Analysis of Circular Data. Cambridge University Press, DOI 10.1017/CBO9780511564345

Gomberg J (2018) Cascadia onshore-offshore site response, submarine sediment mobilization, and earthquake recurrence. Journal of Geophysical Research: Solid Earth 123(2):1381-1404, DOI https://doi.org/10.1002/2017JB014985, URL https://agupubs.onlinelibrary.wiley.com/doi/abs/10.1002/ 2017JB014985, https://agupubs.onlinelibrary.wiley.com/doi/pdf/ 10.1002/2017 JB014985

Gouédard P, Seher T, McGuire JJ, Collins JA, van der Hilst RD (2014) Correction of Ocean-Bottom Seismometer Instrumental Clock Errors Using Ambient Seismic Noise. Bulletin of the Seismological Society of America 104(3):1276-1288, DOI 10.1785/0120130157, URL https://doi.org/10.1785/0120130157, https://pubs.geoscienceworld.org/bssa/article-pdf/104/3/1276/ 2673220/1276.pdf

Hable S, Sigloch K, Barruol G, Stähler SC, Hadziioannou C (2018) Clock errors in land and ocean bottom seismograms: high-accuracy estimates from multiple-component noise cross-correlations. Geophysical Journal International 214(3):2014-2034, DOI 10.1093/gji/ggy236, URL https://doi.org/10.1093/gji/ggy236, https://academic.oup.com/ gji/article-pdf/214/3/2014/25133059/ggy236.pdf 
Hannemann K, Krüger F, Dahm T (2013) Measuring of clock drift rates and static time offsets of ocean bottom stations by means of ambient noise. Geophysical Journal International 196(2):1034-1042, DOI 10.1093/gji/ ggt434, URL https : //doi .org/10.1093/gji/ggt434, https ://academic . oup.com/gji/article-pdf/196/2/1034/1546134/ggt434.pdf

Hilbe M, Anselmetti FS (2015) Mass movement-induced tsunami hazard on perialpine lake lucerne (switzerland): Scenarios and numerical experiments. Pure and Applied Geophysics 172(2):545-568, DOI 10.1007/s00024-014-0907-7, URL https ://doi.org/10.1007/s00024-014-0907-7

Hilbe M, Anselmetti F, Eilertsen R, Hansen L, Wildi W (2011) Subaqueous morphology of lake lucerne (central switzerland): Implications for mass movements and glacial history. Swiss journal of geosciences 104(3):425-443, DOI 10.1007/ s00015-011-0083-z

Hobiger M, Bergamo P, Imperatori W, Panzera F, Lontsi AM, Perron V, Michel C, Burjánek J, Fäh D (2021) Advanced site characterization as part of the renewal project of the Swiss Strong Motion network (SSMNet). Bulletin of the Seismological Society of America Accepted

Jurkevics A (1988) Polarization analysis of three-component array data. Bulletin of the Seismological Society of America 78(5):1725-1743, URL https:// doi.org/, https://pubs.geoscienceworld.org/bssa/article-pdf/78/ 5/1725/2705980/BSSA0780051725.pdf

Lontsi A, Ohrnberger M, Krüger F (2016) Shear wave velocity profile estimation by integrated analysis of active and passive seismic data from small aperture arrays. Journal of Applied Geophysics 130:37 - 52, DOI http://dx.doi. org/10.1016/j.jappgeo.2016.03.034, URL http://www.sciencedirect.com/ science/article/pii/S0926985116300830

Nakamura Y (1989) A method for dynamic characteristics estimations of subsurface using microtremors on the ground surface. Q Rept RTRI Jpn 30:25-33

Poggi V, Fäh D (2010) Estimating rayleigh wave particle motion from threecomponent array analysis of ambient vibrations. Geophysical Journal International 180(1):251-267, DOI 10.1111/j.1365-246X.2009.04402.x, URL http:// dx.doi.org/10.1111/j.1365-246X.2009.04402.x

Preusser F, Reitner JM, Schlüchter C (2010) Distribution, geometry, age and origin of overdeepened valleys and basins in the alps and their foreland. Swiss Journal of Geosciences 103(3):407-426, DOI 10.1007/s00015-010-0044-y, URL https : //doi.org/10.1007/s00015-010-0044-y

Sammartini M, Moernaut J, Kopf A, Stegmann S, Fabbri S, Anselmetti F, Strasser M (2021) Propagation of frontally confined subaqueous landslides: Insights from combining geophysical, sedimentological, and geotechnical analysis. Sedimentary Geology 416:105877, DOI https://doi.org/10.1016/j.sedgeo. 2021.105877, URL https://www.sciencedirect.com/science/article/ pii/S0037073821000294

Schnellmann M, Anselmetti FS, Ward SN (2003) Sturm trotz flaute: Tsunamis auf dem vierwaldstättersee. In: GAIA 12:265-270, DOI https://doi.org/10.14512/gaia. 12.4.10

Schuster G (2009) Seismic interferometry. Cambridge University Press 
Shynkarenko A, Lontsi AM, Kremer K, Bergamo P, Hobiger M, Hallo M, Fäh D (2021) Investigating the subsurface in a shallow water environment using array and single-station ambient vibration techniques. Geophysical Journal International, submitted

Snieder R (2004) Extracting the Green's function from the correlation of coda waves: A derivation based on stationary phase. Phys Rev E 69:046610, DOI 10.1103/ PhysRevE.69.046610, URL http: //link .aps .org/doi/10.1103/PhysRevE. 69.046610

Stachnik JC, Sheehan AF, Zietlow DW, Yang Z, Collins J, Ferris A (2012) Determination of New Zealand Ocean Bottom Seismometer Orientation via RayleighWave Polarization. Seismological Research Letters 83(4):704-713, DOI 10.1785/ 0220110128, URL https://doi.org/10.1785/0220110128, https://pubs . geoscienceworld.org/srl/article-pdf/83/4/704/2763945/704.pdf

Strasser M, Stegmann S, Bussmann F, Anselmetti FS, Rick B, Kopf A (2007) Quantifying subaqueous slope stability during seismic shaking: Lake lucerne as model for ocean margins. Marine Geology 240(1):77 - 97, DOI https://doi. org/10.1016/j.margeo.2007.02.016, URL http://www.sciencedirect.com/ science/article/pii/S0025322707000369

Urgeles R, Leynaud D, Lastras G, Canals M, Mienert J (2006) Back-analysis and failure mechanisms of a large submarine slide on the ebro slope, nw mediterranean. Marine Geology 226(3):185-206, DOI https://doi.org/10.1016/j.margeo. 2005.10.004, URL https://www.sciencedirect.com/science/article/ pii/S002532270500352X

Vanneste M, Madshus C, Socco VL, Maraschini M, Sparrevik PM, Westerdahl H, Duffaut K, Skomedal E, Bjørnarå TI (2011) On the use of the norwegian geotechnical institute's prototype seabed-coupled shear wave vibrator for shallow soil characterization - i. acquisition and processing of multimodal surface waves. Geophysical Journal International 185(1):221-236, DOI 10.1111/j.1365-246X.2011. 04960.x, URL http://dx.doi.org/10.1111/j.1365-246X . 2011.04960.x

Wapenaar K, Draganov D, Snieder R, Campman X, Verdel A (2010) Tutorial on seismic interferometry: Part 1 - basic principles and applications. Geophysics 75(5):75A195-75A209, DOI 10.1190/1.3457445, URL http: //geophysics.geoscienceworld.org/content/75/5/75A195. abstract, http://geophysics.geoscienceworld.org/content/75/5/75A195. full.pdf+html

Wessel P, Smith WHF, Scharroo R, Luis J, Wobbe F (2013) Generic mapping tools: Improved version released. Eos, Transactions American Geophysical Union 94(45):409-410, DOI 10.1002/2013EO450001, URL https : //agupubs . onlinelibrary.wiley.com/doi/abs/10.1002/2013E0450001, https: //agupubs.onlinelibrary.wiley.com/doi/pdf/10.1002/2013E0450001

Zha Y, Webb SC, Menke W (2013) Determining the orientations of ocean bottom seismometers using ambient noise correlation. Geophysical Research Letters 40(14):3585-3590, DOI https://doi.org/10.1002/grl.50698, URL https: //agupubs.onlinelibrary.wiley.com/doi/abs/10.1002/grl.50698, https://agupubs.onlinelibrary.wiley.com/doi/pdf/10.1002/grl. 50698 


\section{Supplementary Files}

This is a list of supplementary files associated with this preprint. Click to download.

- Lontsietal2021main.pdf

- Lontsietal2021supplementary.pdf 